\title{
Response to JRM Task Force Report
}

\author{
By Michael Ralphs, Elaine Grings, and Robert Gillen
}

We commend the SRM Task Force for evaluating the Journal of Range Management's (JRM) status and trend in the field of scientific publication. Periodic reassessment of $J R M$ is important to ensure that this journal continues to be aligned with the needs of the SRM membership. The Task Force has followed a logical course in its attempt to evaluate the impact of the journal, the fields of science included, and JRM's competition. However, other conclusions may be drawn from these results and we appreciate the opportunity to comment on the Task Force's interpretations and recommendations.

The trends in the disciplines publishing in JRM are very interesting. The proportion of papers from Agriculture Science have increased, due mainly to an increase in livestock management papers. Ecology papers have declined and now share a proportion equal to that of livestock management. Monitoring and techniques papers exhibited the largest decline. Perhaps this indicates the evolution of the science. Techniques have been developed over time to measure and quantify the many parameters of rangelands, and are now in use in the ongoing research.

As researchers in livestock management, we publish in JRM because our results apply to the range livestock industry and the land management agencies that deal with grazing. JRM serves that audience. There are also unique opportunities in rangeland systems to use livestock as a land management tool: manipulating wildlife habitat, controlling invasive weeds, or managing land for recreational uses. Managing livestock in a sustainable manner or using livestock to manage for other uses requires an understanding of the basic ecology of the system. Divorcing basic ecology from livestock management by placing that information into separate journals would be counter-productive to the advancement of rangeland science.

There is however, a concern of the increasing number with papers dealing with intensively man- aged introduced pastures from the eastern US. These papers may be out of character with rangeland management and may actually exacerbate our image problem with ecologists.

The decline in ecology papers in JRM and the attitude of range ecologists discriminating against $J R M$, is cause for concern. Over the publication history of $J R M$, there has never been any overtly or conscious discouragement of ecology papers. The Ecology section has always been a prominent section in JRM. As the report illustrated, there has been a proliferation of new ecology journals. Perhaps the competition from other ecological journals or attitudes against livestock grazing have contributed to the decline in ecology papers in JRM.

The question remains, how can we bring the ecology researchers back to JRM. We agree that JRM should change to make itself more appealing to this group. However, we strongly disagree with the recommendation for a new Journal. A new journal by itself would unlikely attract enough ecology papers to make it profitable, and the loss of ecological/monitoring papers would severely cripple $J R M$. We don't think a professional organization the size of SRM should try to support two scientific journals. Other professional societies have two journals, but they are vertically integrated, basic science vs application, not divided by subject matter. We feel there is danger in segregating research by subject matter. Classifying our research by agriculture vs ecology has the potential of driving a wedge in our society. SRM prides itself in its diversity and encourages all who deal with rangelands to become members and get involved with the Society. Segregating our journals by subject matter may have disastrous consequences.

Instead, we recommend that $J R M$ remain as a single journal. SRM should articulate a mission statement for $J R M$ that clearly states the multiple uses of rangelands and emphasizes the ecology component that is basic to the science and management of the 
rangelands. Perhaps a name change for the Journal would emphasize the true breadth of interests within SRM. "Rangeland Science" would be our preference for a new name, but "Rangeland Ecology and Management" might be acceptable. However, a name change by itself will not solve our problems. Only our actions can change our image.

Finally, we believe there is an ethical issue in publishing research. Scientists have the responsibility of publishing results to the audience that can best use the information. Research that could benefit rangeland managers, decision makers and users, be it agriculturally-or ecologically-oriented, should be published in JRM.

We fully agree with the recommendation that $J R M$ should enter the electronic publishing era. It needs to modernize throughout and incorporate electronic submission, review, publishing (while retaining both paper copies, as well as electronic access) and indexing. This would require joint publishing with a company that is set up to handle the business and technicalities of publishing. A publishing company will allow the journal to keep up with the rapid changes occurring in the publishing industry and improve world-wide access, leading to improved implementation of management recommendations stemming from scientific research. This would free up the technical editor and staff to concentrate on the technical quality and direction of $J R M$. Electronic access should be free to SRM members as part of member services, but available to nonmembers on a pay-per-view basis to encourage them to join SRM.

Again, we applaud the $J R M$ Task Force committee for taking the time to throughly evaluate $J R M$ and initiating dialog for change. 